D. C. GEIJSKES

\title{
HET EERSTE INTERNATIONALE CONGRES VOOR DE STUDIE VAN DE PRAE- COLUMBIAANSE CULTUREN IN DE KLEINE ANTILLEN
}

Het Historisch Genootschap in Martinique nam het initiatief om een congres te beleggen over de archeologie van de Kleine Antillen. De reden daartoe was dat Rev. Père Pinchon, een bekend natuuronderzoeker en archeoloog te Fort-de-France, sedert de laatste vijftien jaren belangrijke ontdekkingen had gedaan door opgravingen van Oud-Indiaanse vestigingsplaatsen in Martinique. De mening van Père Pinchon was, dat de overblijfselen in de oudste lagen hadden toebehoord aan de Arowakken, die oorspronkelijk de Kleine Antillen bevolkten, terwijl de jongere lagen de restanten bevatten van de Caraïben, die later de eilanden op de Arowakken veroverden nog tot in de tijd dat Columbus en de eerste Europese zeevaarders de West-Indische eilanden bereikten. De vraag was nu: kunnen wij deze indeling eveneens op de andere Antillen terugvinden en hoever zijn de Caraïben, die ook verondersteld worden te zijn gekomen van het zuidelijk continent, naar het Noorden te vervolgen?

Voor de conferentie hadden zich officieel I37 personen ingeschreven waaronder een groot aantal belangstellenden uit Martinique zelf, terwijl 32 vreemdelingen uit het Caraïbisch Gebied en de U.S.A. tegenwoordig waren. Als afgevaardigde van Suriname was ik de enige deelnemer uit de Guyanas.

Het Eerste Internationale Congres voor de Studie van de Prae-Columbiaanse Culturen in de Kleine Antillen werd van 3-8 juli I96I in het grote Fort St. Louis te Fort-deFrance op Martinique gehouden. De vergaderingen vonden plaats in de Franse Officiers-club, die naast het eigenlijke Fort was gelegen.

In het Fort zelf was de tentoonstelling ingericht van het archeologisch materiaal dat gevonden was op Martinique, hoofd- 
CONGRES VOOR PRAE-COLUMBIAANSE CULTUREN 273

zakelijk bestaande uit de collectie van Père PINchon en van materiaal van andere Kleine Antillen dat door de buitenlandse deelnemers van het congres zelf was meegebracht of dat was ingezonden.

Het tentoongestelde was bijzonder fraai en interessant en bevatte veel zeldzame stukken. De grote collectie van Martinique was verdeeld in Arowaks en Caraïbs materiaal. Mijn eerste indruk was, dat in het Arowakse materiaal verwantschap was te zien met hetgeen in Suriname is gevonden speciaal in de Hertenrits. Het Caraïbse materiaal vertoonde niet de minste overeenkomst met de Surinaamse objecten; enkele stukken deden mij Arowaks aan, een opvatting, die ik later door anderen gedeeld vond. Niettemin was het materiaal het nauwkeurig bekijken meer dan waard.

Naast het rijke materiaal van Martinique, was een prachtige collectie archeologica van Guadeloupe aanwezig, verzameld door Monsieur Edgar CLERC. Zij bestond uit een grote hoeveelheid stenen bijlen, voorwerpen van zeeschelpen gemaakt, aardewerk en schedels, terwijl kaarten bijzonderheden over de vindplaatsen aangaven.

Interessant was ook Mr. Neville Connell's collectie van Barbados, waarin de voorwerpen van zeeschelpen gemaakt de aandacht trokken.

Uit de collectie van Rev. C. JEsse was van St. Lucia een verzameling stenen bijlen in diverse typen en een aantal interessante potscherven aanwezig. Mr. Thomas CAMBrIDGE had uit zijn collectie van Tobago o.a. enkele met menselijke koppen prachtig versierde Arowakse vaasfragmenten meegebracht.

Van Suriname bracht ik 78 voorwerpen mee uit de archeologische collectie van het Surinaams Museum, terwijl een kaart en vele foto's een overzicht gaven van wat wij heden kennen van het Arowakken en Caraïben materiaal uit de prae-columbiaanse tijd van dit gedeelte van het Zuidamerikaanse continent.

In enkele vitrines waren boeken en publicaties tentoongesteld om een overzicht te geven van wat er over de Kleine Antillen en omgeving op archeologisch gebied verschenen is.

Als geheel vormde deze tentoonstelling een zeer belangrlijk onderdeel van het congres, dat vergelijkingen vergemakkelijkte en onderzoek stimuleerde. Alle moeite en zorg hieraan besteed, was volkomen verantwoord en werd bijzonder gewaardeerd. 
De vergaderingen stonden onder leiding van Père Pinchon, President van het congres, geassissisteerd door Mr. Jacques Petitjean-Roget, President van het Historisch Genootschap van Martinique. De voertaal was Frans, maar de meeste buitenlanders waren van de Engels sprekende gebieden. Mr. Henri THEUVEnin heeft op bewonderenswaardige wijze de directe vertalingen geleverd, zowel uit het Frans naar het Engels als omgekeerd. Het gesprokene, ook in de discussies, werd op een taperecorder opgenomen en vastgelegd.

Het congres werd door de Préfet van Martinique geopend, waarna de President de la Société d'Histoire de la Martinique een voordracht hield over "La culture Caraïbe à travers le dictionnaire du R.P. Breton." Deze missionaris leefde onder de 'Carribbeans' van r635 tot I654 in Dominica. Volgens Breton werd het woord 'Carribbean' door de Spanjaarden gebruikt voor de oorspronkelijke bewoners van de Kleine Antillen, terwijl zij zichzelf 'Kalinago' noemden. Zij werden verondersteld te zijn gekomen van het zuidelijk continent, waar nu hun broeders de 'Galibis' nog leven. Zij vermoordden de 'Allouagues' en hielden hun vrouwen als slavinnen. Deze vrouwen spraken arowaks en leerden die taal ook aan hun kinderen; de mannen spraken de caraïbse taal. Later kwam de vermenging, zoals ook zou blijken uit de naam voor Martinique 'Inuacaera' dat 'eiland van de leguanen' betekent.

In zijn verdere betoog over de levenswijze en de toiletgeheimen werd een beeld geschilderd van het Indianenleven, zoals wij dat in Suriname, niet ver van Paramaribo, ook thans nog kunnen meemaken. Eens te meer werd het mij duidelijk dat wij dankbaar mogen zijn voor zulk een rijkdom aan gegevens over Indianen in Suriname, die elders, waar deze bevolkingsgroep door de westerse civilisatie reeds lang is verdwenen, met moeite uit de oude kronieken kunnen worden gereconstrueerd. Toch blijft de studie van de vroegere scheepsjournalen waarin de eerste ontmoetingen met de toenmalige Indiaanse bevolking staan opgetekend, een onmisbare schakel in het archeologisch Indianen-onderzoek. Het is toe te juichen dat een bestudering van de Spaanse archieven met het oog hierop plaats vindt en wordt aangemoedigd. Maar ook in andere landen als Frankrijk en Engeland en wellicht zelfs in Nederland, zullen stellig nog vele bruikbare gegevens schuilen.

In een voordracht van Père PINCHON over "Le Problème archéologique à la Martinique, vue d'ensemble" werden de ver- 
schillende technieken van het pottenbakken behandeld, die in de prae-columbiaanse tijd zijn toegepast. Hij onderscheidde 'moulding' en 'coiling'. 'Moulding' is de techniek waarbij een pot uit verschillende onderdelen wordt samengesteld door samenvoeging op de randen van deze delen. Zo kan een pot uit twee of meer gedeelten zijn opgebouwd, waarbij deze delen gewoonlijk met elkaar een hoek maken. Op deze hoekpunten zijn de potten dikwijls afgebroken. De tweede techniek is 'coiling' waarbij een pot uit kleirollen, die door gladstrijken aan elkaar worden gevoegd, wordt opgebouwd.

Volgens Père Pinchon zijn deze technieken niet uit elkaar ontstaan, maar zijn onafhankelijk van elkaar in twee verschillende culturen toegepast. 'Moulding' zou eerder zijn gebruikt dan 'coiling', want het wordt gevonden bij aardewerk van Arowakken op Trinidad en in Martinique van naar schatting 2000 jaar geleden. 'Coiling' is in Martinique gevonden in de tijd van Columbus. Er zijn helaas nog geen ouderdomsbepalingen gedaan door middel van radio-carboon ( $\mathrm{C}_{\text {I4 }}$ ) onderzoek, maar men vindt ter plaatse de twee technieken door een grote aslaag gescheiden als gevolg van een grote eruptie van de Mont Pelée die in praecolumbiaanse tijd moet hebben plaats gevonden. Spreker ziet hierin twee migraties nl. die van de Arowakken en die van de Caraïben.

Bij de discussie werd de kwestie besproken of deze verschillen in baktechniek leeftijdsverschillen en rassenverschillen inhouden. Volgens Prof. Rouse, Prof. Haag en Prof. Bullen (allen Amerikanen) was dit niet het geval. Na de voordracht volgde een demonstratie door een creoolse vrouw van Anse in Martinique die door 'coiling' enkele pot-modellen maakte, welke in vorm gelijkenis vertoonden met Indiaanse 'prapies' en kookpotjes zoals we die van de Caraïben uit Suriname kennen. Bij deze gelegenheid had ik graag een film laten zien (als die er geweest was!) van het pottenbakken zoals dit door onze Caraïbse vrouwen nog steeds wordt toegepast. Ook daarbij wordt de methode van 'coiling' gebruikt.

Père Pinchon wees in zijn voordracht over: "Les différentes formes de Céramique dans la civilisation arawak" op de verschillen die bestaan tussen het bakwerk van de Arowakken en de Caraïben. Er is vaatwerk voor huiselijk gebruik en voor ritueel gebruik. De eerste missen ornamenten maar kunnen wel pot-oren of pot-aanvatsels bezitten. Hiertoe behoren ook ronde kommen en karaffen of waterkruiken, alsmede platte dikke platen voor het bakken van cassavebrood. Kashiri-potten tot 50 liter inhoud waren vermoedelijk niet transportabel. 
Bij rituele potten zijn de aanvatsels versierd met koppen, waarvan de gezichten naar het binnenste van de pot kijken. Ook zijn een soort platte lampen gevonden die met een kop zijn versierd, met daartegenover een tuitje om olie te laten branden. In de onderste lagen zijn in Martinique veel beschilderde scherven gevonden. De polychroomkleuren zijn op het aardewerk aangebracht vóór het branden van de potten. Degenen die de potten hebben gemaakt zijn zeker artistiek van aanleg geweest (Arowakken). Volgens Père Pinchon zou deze cultuur snel zijn vernietigd door de komst van de Caraïben.

De Caraïben maakten potten met drie pootjes (oorspronkelijk werden drie stenen onder een kookpot gelegd). De Arowakken maakten geen pootjes onder hun potten. In het Caraïbse aardewerk vinden we ook aan de buitenkant van de potten gezichten en figuurtjes van mensen en dieren terwijl bij de Arowakken deze decoraties alleen aan de pot-oren en aanvatsels voorkomen. Ook maakten de Caraïben poppetjes met grove lichamen en fijner afgewerkte gezichten. De poppetjes hebben een andere betekenis gehad dan de figuurtjes op de potten, doch aan beide typen mag een rituele betekenis ten grondslag liggen. Voor beide groepen zijn de spingewichten die in de spindel gebruikt zijn, gelijk geweest; ze hebben een centrale holte, maar ze zijn niet versierd.

Prof. Fred. OLSEN sprak over "Arawak diggings in Antigua." Spreker groef 200.000 scherven op uit verschillende vindplaatsen, waarop veel beeldjes en gezichten werden aangetroffen. Ook cassave-bakplaten met twee lange opstaande aanvatsels zijn gevonden. Volgens de radio-carboon datering was dit Arowakse materiaal gemaakt en gebruikt omstreeks 500 jaar v. Chr.

Prof. William G. HAAG (Univ. of Louisiana) gaf in een voordracht (met color-slides) zijn ervaringen weer over een onderzoek op St. Lucia. Daar waren de Arowakken nederzettingen overheersend. De Indiaanse restanten werden tot $2 \mathrm{~m}$ diepte gevonden in zandduinen die roo $\mathrm{m}$ van de zee lagen. Er lagen potscherven en stenen voorwerpen. Er werden ook potten aangetroffen met drie vrij lange poten er onder, die niet mooi waren afgewerkt. Vermoedelijk was dit Caraïbs materiaal. De methode van onderzoek kwam neer op het maken van series, vandaar de benaming 'Seriation', en bestond uit het afsteken van een kubieke halve voet grond, die na drogen werd uitgezeefd. Het zo verkregen materiaal werd in monsterzakjes gedaan en later gesorteerd "in a single subject of pottery" in diverse hoogten van het totale profiel. Zo krijgt men een goede stratigrafie met nauwkeurige series die onderling veel vergelijkingen toelaten. De methode is echter alleen in grote profielen toe te passen.

Op deze wijze werden in St. Lucia in de diepere lagen potscherven met lijnen-decoratie gevonden. Er lagen ook veel gekleurde scherven, wit en rood, terwijl wit, rood en zwart alleen in de diepste lagen voorkwam. Op meer dan $2 \mathrm{~m}$ diepte trof Prof. Haag rood gekleurde potscherven aan met uitsteeksels erop, terwijl rood en zwart gebandeerde tekeningen op de potscherven in dezelfde laag te vinden waren. De figuurtjes op het bakwerk liepen in stijl van Arowakken en Caraïben door elkaar. In sieraden van schelp gemaakt, kwamen gestyleerde kikkerfiguren voor.

Merkwaardig en typisch waren 'potsets' of 'potstands' van bakwerk 
als een pot zonder bodem met een nauwe halsopening, waarbij de buik in een bijna scherpe hoek overging in de hals.

In de profielen was van boven naar beneden geen verschil in de voedselresten (botten van dieren) te zien. Er lagen veel landslakken tussen en slechts tien grote zeeslakken ('Conchus'), terwijl het strand er vol mee lag.

Potscherven waren veel talrijker dan de stenen voorwerpen. Er werd een skelet gevonden in zittende houding met het hoofd voorovergebogen.

De conclusie van Prof. Haag was dat in St. Lucia bepaalde elementen in de verschillende vindplaatsen vergelijkbaar zijn, maar dat Arowakken en Caraïben zich niet goed laten onderscheiden.

In zijn tweede voordracht over "Comparison of so-called Carib sites in the Lesser Antilles" zette Prof. Haag de bijzonderheden uiteen die hem bekend zijn geworden van de zg. Caraïben nederzettingen in Martinique en St. Lucia. Hij vond vindplaatsen met schelpen en nederzettingen zonder schelpen. Er bestond ook verschil in pottenbakkers-werk tussen beide typen. Dit wijst op twee verschillende culturen of op een differentiatie van een cultuur. Het type met schelpen en ruw aardewerk wordt Caraïbs genoemd (als ook aangenomen door Père Pinchon). Prof. Haag is niet zeker of dit wel Caraībs is. Nederzettingen van dit type zijn gevonden in Martinique, Guadeloupe en Antigua enerzijds en in St. Lucia, St. Vincent en vermoedelijk ook in Noord Trinidad anderzijds. Typisch is ook dat er veel scherven aan de oppervlakte liggen (b.v. in Paquemar in Martinique, dat tijdens een excursie bezocht werd), terwijl de plekken weinig boven zee-niveau liggen en niet dieper dan $1 \mathrm{~m}$ onder het oppervlak gaan. Onder het pottenbakkerswerk zijn open schalen met vingerafdrukken op de rand zeer typisch, evenals cylindrische 'potstands'. (Hetzelfde is mij van de Hertenrits uit Suriname bekend). Er komen ook cassavebakplaten (griddles) in voor, hetgeen duidt op teelt van cassave. Gebruik van zeeproducten als voedsel (van de koraalriffen o.a.), blijkt uit de vele zeeschelpen. Ook hier zijn kookpotten met drie pootjes gevonden, alsmede platte schalen met een cylindrisch handvat.

Op de scherven komt een versiering voor van ruwe en fijne lijnen en een arcering van schuine lijnen (criss-cross stripes) en brede strepen parallel in ronde bogen getrokken. Onder de kopfiguren is de leguanenkop kenmerkend, maar er komen geen 'coffee beans' als ogen in voor. Ook driehoekige huidstempels (bodystamps) met ronde concentrische figuren zijn aangetroffen en kraalvormige gewichten voor de spindels (spindelwhorls). De stenen bijlen in deze nederzettingen zijn van het ronde type als voorkomend op de Kleine Antillen, of behoren tot de schouderbijlen (winged or eared axes) ook bekend van Suriname. De verschillende voorwerpen wijzen volgens Prof. Haag op diverse stadia van ontwikkeling of op een meerdere malen plaats gehad hebbende migratie.

Prof. Ripley P. Bullen (State Museum, Gainesville, Florida) deelde een en ander mede over zijn opgravingen in de noordelijke Kleine Antillen in zijn voordracht over: "The Cupecoysite in St. Marteen, a comparison of its potteries with that from the Virgin Islands and Antigua." Spreker zag een samenhang tussen de $\mathrm{zg}$. Caraïbse nederzettingen in Martinique en die op Saba, St. Eustatius en St. Maarten. Archeologisch gesproken ligt de grens van de Grote en de Kleine Antillen tussen Puerto Rico en de Virgin Islands. Op de Virgin Islands en Antigua zijn ook platte schalen met een versiering op de rand van indrukken van vingertoppen gevonden 
als te Paquemar in Martinique. Voorwerpen gemaakt van 'greenstone' worden algemeen gevonden in de Grote Antillen en ten dele ook in de Kleine Antillen. Het is mogelijk om deze steensoorten te analyseren en zo de handelswegen vast te leggen. Prof. Bullen wil aantonen dat de oudste lagen als gevonden in Martinique, op een jonger niveau zijn terug te vinden in St. John en St. Thomas. Dit zou op een migratie vanuit het Zuiden wijzen.

In een tweede voordracht behandelde Prof. Bullen de vondsten van "A preceramic workshop at Krumbay in the Virgin Islands" waarin geen aardewerk maar alleen stenen voorwerpen van een primitief type werden aangetroffen. Het zijn restanten van de oudste bewoners die vermoedelijk geen Arowakken waren, maar wellicht via de Grote Antillen uit Florida van het Noordelijk Amerikaans continent gekomen zijn.

Prof. Irving Rouse (Yale University, New Haven Conn. U.S.A.) gaf in zijn voordracht "The Development of Precolumbian art in the West Indies" een overzicht van zijn onderzoekingen op de Grote Antillen. Het pottenbakwerk geeft de cultuur aan, bedreven door vrouwen; de stenen voorwerpen demonstreren de kunst van de mannen. De Arowakken waren godsdienstige mensen en zij maakten ook rituele stenen voorwerpen. Zulke stenen zijn niet alleen in de Grote Antillen gevonden maar ook in de Kleine Antillen. Deze 'art in stone' is door de komst van de Caraïben op de Kleine Antillen afgekapt, maar is op de Grote Antillen blijven bestaan omdat de Caraïben niet zover noordelijk zijn doorgedrongen.

Stenen voorwerpen hebben het bezwaar dat ze moeilijk te dateren zijn. Op de grote Antillen zijn vier perioden te onderscheiden: de oudste bevat alleen stenen voorwerpen en geen aardewerk. Periode twee, drie en vier geven de Arowakse culturen te zien in volle ontwikkeling, hoger dan op de Kleine Antillen voorkomt. Het begin van periode vier lag omstreeks I 100 of 1200 jaar n. Chr. en viel samen met de inval van de Caraïben op de Kleine Antillen. De vindplaatsen van de eerste twee perioden liggen alle langs de kust, terwijl die van drie en vier ook in het bergachtige binnenland gevonden worden. Men neemt aan dat dit als bescherming tegen de overvallen van de Caraïben is gedaan.

In een latere bespreking kwamen Prof. Rouse en Père Pinchon tot de conclusie dat in Martinique twee culturen te onderscheiden zijn die door Père Pinchon zijn aangeduid als:

(I) Arowak in 2 facies

a Marigot, St. Marie (= periode 2 van Rouse in Puerto Rico)

$a_{2}$ Vive

(2) Caraïb in 2 facies

$\mathrm{b}_{1}$ Belleville en St. Lucie (= periode 3 van Rouse in Puerto Rico)

$\mathrm{b}_{2}$ Paquemar en St. Lucie

Volgens Rouse kwamen de bewoners van periode 2 in Puerto Rico via de Kleine Antillen, terwijl in periode 3 pottenbakkerswerk is gevonden dat van de Kleine Antillen afkomstig kan zijn. In periode 4 is dit echter niet meer het geval.

Veel zal met $\mathrm{C}_{\mathrm{I}_{4}}$ analyses (radio-carboon dateringen) moeten worden aangevuld om vergelijkingen mogelijk te maken.

Monsieur Edgar CLERC bracht in zijn voordracht "Sites précolombiens à sépulture à la Guadeloupe" de resultaten van zijn archeologisch onder- 
zoek op dit eiland naar voren. Spreker onderzocht twee vindplaatsen van oud-Indiaanse nederzettingen aan de noordkust, waar koraalbanken met ondiep kalm water voorkomen en lagunes met hogere plekken voor woonplaatsen en landbouw gevonden worden.

De resten lagen van $1.50-3 \mathrm{~m}$ diep. Clerc kon daarin drie horizonten onderscheiden, die van beneden naar boven als volgt gekenmerkt zijn:

(I) bakwerk met veel dierenkoppen (zoömorphisch) en mensenkoppen (anthropomorphisch) als versiering;

(2) bakwerk met krasfiguren en potscherven in drie kleuren wit, rood en zwart, en tevens platte schalen en borden en waterkruiken met kleine tuit;

(3) ruw aardewerk zonder versiering (jongste laag)

Er werden ook drie-puntstenen gevonden (onversierd) zoals bekend van de Grote Antillen. Urnen en skeletten kwamen voor in alle lagen. De skeletten in de re en de ze laag lagen gestrekt en waren bedekt met zand. Volgens berekening naar een scheenbeen, moet de persoon in kwestie ca $1.70 \mathrm{~m}$ lang zijn geweest. De meeste beenderen waren door kalk aan elkaar gekit.

De skeletten in de 3 e laag werden in verschillende standen gevonden, o.a. zittend met een bord als een chinese hoed op het hoofd. Deformatie van de schedel komt voor met een gelaatshoek van $110^{\circ}$ (in plaats van $94^{\circ}$ ).

Uit deze waarnemingen bleek met hetgeen reeds ter tafel was gebracht door Père Pinchon en Prof. Haag, dat aansluiting met Martinique en met St. Lucia duidelijk was en dat contact van de vroegere bewoners van Guadeloupe met de Grote Antillen moet hebben bestaan, gezien de aanwezigheid van de driehoekige puntstenen. De skeletvondsten betekenden een extra aanwinst.

Père Pinchon vestigde in zijn voordracht over "Originalité de quelques iles dans le travail de la pierre polie" de aandacht op de specialiteit van bijna elk eiland voor wat betreft het voorkomen en de vorm van stenen voorwerpen. In Martinique zijn weinig mooie stenen voorwerpen gevonden, maar in St. Lucia en op Guadeloupe komen ze veel voor. Ze zijn daar niet alleen tussen potscherven gevonden in de woonplaatsen langs de kust, maar ook in het midden van het eiland zonder dat er potscherven bij lagen. Voor St. Lucia is een grote stenen bijl rechthoekig van vorm met brede 'schouders' zeer typisch. Hetzelfde type is niet noordelijker, maar wel zuidelijker op St. Vincent teruggevonden. Eveneens typisch voor St. Lucia is een petaloïde bijl van 'greenstone' van 12 tot $20 \mathrm{~cm}$ lang, maar ook kleinere uitgaven tot 5 en $6 \mathrm{~cm}$ lang, mooi gepolijst, zijn daar aangetroffen en werden misschien als amuletten gebruikt. Iets dergelijks is ook op Martinique gevonden.

Op de noordelijke eilanden van de Kleine Antillen tot St. Maarten zijn een soort tomahawks van steen gevonden. Op St. Kitts zijn veel halve manen van vulkanische steen aangetroffen. In Martinique kent men van de Mont Pelée kralen van amethyst, terwijl op Antigua ook veel stenen kralen gevonden zijn. Zo geeft iedere streek zijn eigen specialiteit op het gebied van stenen voorwerpen te zien. Het feit echter dat op de Kleine Antillen geen ruwe onafgewerkte stenen bijlen zijn gevonden, zou ook kunnen wijzen op een ruilhandel van het continent. In het laatste geval zou dit petrografisch te traceren zijn. 
In mijn voordracht over "Arowaks in the prehistory of Surinam" (toegelicht met color-slides), had ik gelegenheid om de vondsten van de Hertenrits in Nickerie te behandelen en gegevens over andere vindplaatsen van Arowakken in het kustgebied naar voren te brengen. Uit het bakwerk bleek de verwantschap met het Arowakken materiaal van de Antillen. In tegenstelling echter met de Antillen nam de versiering van het bakwerk van de oudste naar de jongste lagen toe. Ook de platte schalen met vingertopindrukken op de rand (als bekend van St. Lucia en Martinique) en cylindervormige 'potsets' zijn hier gevonden, echter geen potten met 3 voetjes. De pot-oren en pot-aanvatsels zijn in de jongere lagen dikwijls versierd met dierkopjes en mensengezichten welke in de pot kijken.

Half of weinig bewerkte stenen van kwarts lagen er veel, maar gaaf afgewerkte stenen bijlen en klopstenen weinig. De bijlen waren van het petaloïde en het gevleugelde type. Een enkele fraai gepolijste kikkerfiguur van 'greenstone' is hier eveneens gevonden. Van de grote zeeslak Melongena melongena zijn een aantal kleine sieraden en mesjes gemaakt.

In de Hertenrits zijn een paar menselijke skeletten gevonden die gestrekt op $60 \mathrm{~cm}$ diepte lagen, het hoofd met een schaal of pot afgedekt. De lengte van deze mensen was I60-I65 $\mathrm{cm}$ en hun schedel behoorde tot het brachycephale (ronde) type (op Guadeloupe, Curaçao en Aruba waren de schedels van het longicephale (= dolichocephale, lange) type).

Naast de bijzonderheid dat de Hertenrits een opgeworpen terp in de uitgestrekte klei-zwampen is, zijn landbouwbedden van Io-IOo m lengte en $5 \mathrm{~m}$ breedte - zoals gevonden rondom de Hertenrits tot een afstand van $5 \mathrm{~km}$ - een onbekend verschijnsel op de bergachtige Antillen. Radio-carboon analyses hebben uitgewezen dat de Hertenrits I200-I050 jaren geleden bewoond is geweest.

In mijn tweede voordracht heb ik de 'Koriabo-phase' van de Caraïben behandeld. De meeste vindplaatsen van vroegere bewoning in Suriname behoren tot deze groep. Ze worden gevonden op de ritsen in het kustgebied, op de zandsavannen en langs de hogere rivier-oevers in het binnenland. Verkeer te water heeft plaats gehad over de grote rivieren en over de boskreken. Van kustvaart is niets bekend.

Het pottenbakkerswerk is te herkennen aan de lijnversieringen, door ingekraste figuren en aan het appliqué-werk met 'coffee beans' en andere ornamenten, die op de buitenkant van de potten 
aangebracht werden. De aanvatsels waren ook met dierkoppen versierd; de gezichten kijken echter naar buiten en niet in de pot zoals bij de Arowakken. Sierkommen hebben een gelobde rand die naar buiten is uitgebogen en aan de binnenkant met lijnen streepfiguren is versierd.

De modellen van de kookpotten zijn zeer typisch; ze hebben nl. een kleine bodem, een sterk divergerend buikgedeelte en een rechtstandige hals met wijde opening, de rand bijna rechthoekig naar buiten omgebogen. Over het algemeen is dit bakwerk veel dunner dan dat van de Arowakken. Wel komen dikke bakplaten voor, die gediend hebben voor het bakken van cassavebrood. Als verschralings-middel gebruikte men bij het bakken scherp zand.

De Koriabo Indianen gebruikten veel stenen voorwerpen zoals stenen bijlen in rechthoekige, afgeronde en petaloïde modellen, wrijf- en klopstenen, maalstenen voor het kneuzen van palmpitten, beitels en slijpstenen. Deze zijn uit verschillende steensoorten gemaakt, met een voorkeur voor dioriet, 'greenstone' en graniet. Een enkele maal zijn sierstenen van jade in de vorm van een kikker of een vis gevonden. Deze moeten zijn geïmporteerd, wellicht uit het Amazone-gebied, omdat jade in Suriname slechts in kleine adertjes gevonden wordt. Kralen van kwarts zijn ook bekend. Sieraden van schelpen echter niet.

Met behulp van de radio-carboon (C-I4) analyses is komen vast te staan dat de Koriabo-phase in Suriname ruim 1800 jaren heeft bestaan, want de oudste dateringen waren van \pm 2300 jaren en de jongste van \pm 500 jaren.

Door hetgeen ik op de tentoonstelling zag van zg. Caraïbs aardewerk en bijbehorende stenen voorwerpen van de Kleine Antillen, speciaal van Martinique, werd het mij duidelijk dat dit materiaal in geen enkel opzicht aansluiting te zien geeft met het Caraibse materiaal van de Guyanas. De mening dat de Caraïben van de Guyanas over zee langs de kust naar het Westen zouden zijn getrokken met wind en stroom mee tot de Antillen eilanden waren bereikt, blijkt een fabeltje te zijn dat op geen enkel archeologisch bewijs steunt. De Caraïben, indien ze het inderdaad zijn geweest die de raids op de Arowakken-bevolking van de Antillen hebben uitgevoerd, zijn naar mijn mening niet van de Guyanas afkomstig, doch van elders, misschien uit het Orinoco gebied of uit westelijker Venezuela. Het zg. Caraïben materiaal van de Kleine Antillen komt veel meer overeen met de voor- 
werpen van de Hertenrits dan met de restanten uit de Koriabophase. Het was ook de mening van de Amerikaanse onderzoekers Prof. Haag, Prof. Rouse, Prof. Bullen en Prof. Olsen, die ik tijdens de conferentie en bij de rondgang door de tentoonstelling over deze kwestie gesproken heb, dat het zg. Caraïben materiaal van de Kleine Antillen en speciaal van Martinique (Paquemar) eerder een vorm van Arowakken materiaal voorstelt dan van Caraïbs materiaal. Men had echter weinig ervaring met het Caraïben type, omdat dit een zaak is van het tropisch Zuidamerikaanse continent.

De invloed van de Caraïben op de archeologie van de Kleine Antillen is hiermede niet duidelijker geworden. Integendeel, het hele probleem is in de lucht komen te hangen en zal alleen door nauwkeurig archeologisch onderzoek van de basis-eilanden en van de kust van Venezuela vaste grond onder de voeten krijgen. Wij volgen daarom met grote belangstelling het onderzoek van Prof. Rouse en Prof. Cruxent van Caracas, dat thans langs de kust van Venezuela tegenover Trinidad wordt uitgevoerd naar de nederzettingen van de oudste bewoners van dit gebied

Interessant waren ook de opmerkingen van Dr. M. J. A.BulLBROOK, Curator van The Royal Victoria Institute Museum Portof-Spain, Trinidad, die in de slotzitting meedeelde dat Trinidad alleen bewoond is geweest door Arowakken en dat de sporen van Caraïben niet duidelijk zijn, zo niet geheel ontbreken.

Er zijn geen planken met steentjes gevonden als gebruikt om cassave te raspen (zoals nu nog bij de Bovenlandse Caraïbse Indianen in Suriname gebeurt). De banaan is ingevoerd en werd niet oorspronkelijk door de Indianen gebruikt. Er is ook enig verschil in voedsel (zeeschelpen) te zien o.a. in twee dicht bij elkaar gelegen oud-Indiaanse nederzettingen in het Zuiden van Trinidad, waarbij in de ene (Palo Seco) veel Neritina en Cyrena en in de andere (Erin) weinig Neritina en veel Cyrena te vinden waren. De eerste plek is ouder dan de tweede. Een skelet in Erin lag op een zijde en was niet in zittende houding gevonden zoals in St. Lucia (Haag) en in Guadeloupe (Clerc). In Erin werd ook een prachtige pot aangetroffen in de vorm van een mensenkop en een lamp als een platte pan met een tuit. Dr. Bullbrook heeft critiek op de radiocarboon-dateringen en twijfelt aan de betrouwbaarheid. Hij zag graag een chemisch en spectografisch onderzoek van de verfstoffen en wil hulp laten bieden door specialisten bij het anatomisch onderzoek van skeletten. 
Mr. Neville Connell, Directeur van het Barbados Museum, gevraagd naar zijn mening over het voorkomen van Caraïben in Barbados, deelde mede dat de Arowakken door de schepelingen ook Caraïben genoemd werden. Het archeologisch onderzoek in Barbados heeft tot nu toe alleen Arowaks materiaal voor den dag gebracht met veel werktuigen en sieraden van zeeschelpen gemaakt.

Prof. Rouse vestigt de aandacht op enkele typische stenen voorwerpen van de Grote Antillen die ongelijk verspreid over de Kleine Antillen zijn teruggevonden en in Trinidad niet in de 'middens' of oude vestigingsplaatsen werden aangetroffen, maar incidenteel aan de oppervlakte.

Ik was het ook geheel eens met de uitspraak van Prof. HAAG in de slotzitting van het congres dat het te vroeg is om definitieve conclusies te trekken, omdat we nog te weinig in detail kennen om vergelijkingen te maken.

Terecht wees Père Pinchon op onze leemte in kennis aangaande verschillende eilanden, zoals Dominica, St. Kitts enz., waar het archeologisch onderzoek nog moet beginnen. Men moet niet alleen een studie maken van de potscherven, potten en stenen voorwerpen, maar men moet ook de nederzettingen en vindplaatsen zelf in het onderzoek betrekken. Tot nu toe is aan dit veldwerk te weinig aandacht besteed.

Van Amerikaanse zijde werd vooral aangedrongen op een datering met $\mathrm{C}-\mathrm{I} 4$ analyses om ouderdomsbepalingen te krijgen voor een vergelijkbare tijdsindeling.

Aan het einde gekomen van de besprekingen voelde een ieder die aan dit congres had deelgenomen, dat er stellig iets goeds bereikt was. Er was een overzicht verkregen van de huidige stand van het archeologisch onderzoek op de Kleine Antillen en op het aangrenzende gebied. Er was persoonlijk contact gemaakt tussen de onderzoekers in een vriendschappelijke sfeer, die de gedachtenwisseling tijdens de discussies en in gesprekken ten goede kwam. Er was door de gastvrijheid van de leden van het Historisch Genootschap in Martinique gelegenheid geboden om tijdens twee excursies een indruk te krijgen van het eiland en van de archeologische vindplaatsen die veel verduidelijkten van wat aan de conferentie-tafel daarover in theorie was medegedeeld.

Met veel enthousiasme was de tentoonstelling in elkaar gezet die een uniek overzicht gaf van het Oud Indiaanse materiaal van de Kleine Antillen. 


\section{CONGRES VOOR PRAE-COLUMBIAANSE CULTUREN}

$\mathrm{Al}$ dit werk had resultaat gehad en kon niet in een afscheid met een slok champagne worden weggespoeld. Het moest worden voortgezet, daar was men het unaniem over eens. Het werd in een resolutie van de delegatie van Trinidad tot uiting gebracht met de volgende woorden:

"Be it resolved that in view of the need for correlating archaeological discoveries both in the Antillean islands and in the Mainland, and the obvious need for the closest collaboration between the participating units of this congress which is representative of the countries of the New World, that there be constituted an association of all archaeological interests in these parts, which may be known as the INTERNATIONAL ASSOCIATION FOR CARIBBEAN ARCHEOLOGY and that this council shall call upon the United Nations to accept it as a duly constituted international body, under the arm of UNESCO to fulfil its worthy purposes."

Het ligt in de bedoeling om elke drie jaren op een van de Antillen eilanden bijeen te komen, teneinde van de jongste ontwikkelingen op archeologisch gebied op de hoogte te blijven, het werk te stimuleren en eventuele richtlijnen te kunnen uitzetten. Moge de oprichting van deze 'association' het succes van dit eerste congres bestendigen.

\section{SUMMARY}

THE FIRST INTERNATIONAL CONGRESS FOR STUDY OF THE PRE-COLUMBIAN CULTURES IN THE LESSER ANTILLES

The 'Premier Congrès international d'Études des civilisations précolombiennes aux Petites Antilles' was held in Martinique from 3rd to 8th July, 196r. Its theme was: the influence of the Palaeo-Indian population of Arawaks and Caribs on the Lesser Antilles. The congress was attended by over 130 people, including about 30 non-Martiniquais.

It was found that the articles discovered in the Lesser Antilles showed close similarities to each other, but that each island could point to objects peculiar to itself. Study of potsherds revealed no clear distinction between the products of Arawaks and those of Caribs. The numerous discoveries in Trinidad relate only to Arawaks. Comparison with Suriname revealed that the Arawak objects found showed a connection with Venezuela and the Antilles, but that the relics of the former Caribs showed no connection with the Caribbean region. The story that the Caribs of the 'Wild Coast' drove out and replaced the Arawaks in the Antilles has not been proved archaeologically.

It was proposed that an International Association should be formed with the object of promoting study of the archaeology of the Caribbean area, inter alia by holding a congress on one of the islands every three years. 